\title{
Triiodothyronine Acutely Stimulates Glucose Transport into L6 Muscle Cells Without Increasing Surface GLUT4, GLUT1, or GLUT3
}

\author{
Silvania Silva Teixeira, ${ }^{1}$ Akhilesh K. Tamrakar, ${ }^{2}$ Francemilson Goulart-Silva, ${ }^{1}$ \\ Caroline Serrano-Nascimento,' Amira Klip,, ${ }^{3,4}$ and Maria Tereza Nunes ${ }^{1}$
}

Background: Thyroid hormones (THs) act genomically to stimulate glucose transport by elevating glucose transporter (Slc2a) expression and glucose utilization by cells. However, nongenomic effects of THs are now emerging. Here, we assess how triiodothyronine $\left(\mathrm{T}_{3}\right)$ acutely affects glucose transport and the content of GLUT4, GLUT1, and GLUT3 at the surface of muscle cells, and possible interactions between $\mathrm{T}_{3}$ and insulin action.

Methods: Differentiated L6 myotubes transfected with myc-tagged Slc2a4 (L6-GLUT4myc) or Slc2a1 (L6GLUT1myc) and wild-type L6 myotubes were studied in the following conditions: control, hypothyroid (Tx), Tx plus $\mathrm{T}_{3}$, Tx plus insulin, and Tx plus insulin and $\mathrm{T}_{3}$.

Results: Glucose uptake and GLUT4 content at the cell surface decreased in the Tx group relative to controls. $\mathrm{T}_{3}$ treatment for 30 minutes increased glucose transport into L6-GLUT4myc cells without altering surface GLUT4 content, which increased only thereafter. The total amount of GLUT4 protein remained unchanged among the groups studied. The surface GLUT1 content of L6-GLUT1myc cells also remained unaltered after $\mathrm{T}_{3}$ treatment; however, in these cells glucose transport was not stimulated by $\mathrm{T}_{3}$. In wild-type L6 cells, although $\mathrm{T}_{3}$ treatment increased the total amount of GLUT3, it did not change the surface GLUT3 content. Moreover, within 30 minutes, $T_{3}$ stimulation of glucose uptake was additive to that of insulin in L6-GLUT4myc cells. As expected, insulin elevated surface GLUT4 content and glucose uptake. However, interestingly, surface GLUT4 content remained unchanged or even dropped with $\mathrm{T}_{3}$ plus insulin.

Conclusions: These data reveal that $\mathrm{T}_{3}$ rapidly increases glucose uptake in L6-GLUT4myc cells, which, at least for 30 minutes, did not depend on an increment in GLUT4 at the cell surface yet potentiates insulin action. We propose that this rapid $\mathrm{T}_{3}$ effect involves activation of GLUT4 transporters at the cell surface, but cannot discount the involvement of an unknown GLUT.

\section{Introduction}

$\mathbf{T}$ HYROID HORMONES (THs) increase glucose consumption by cells (1), by enhancing the expression of oxidative and glycolytic enzymes (2) and glucose transporter 4 (GLUT4) $(3,4)$. GLUT4 is the unique GLUT isoform regulated by insulin, and considering the high prevalence of diabetes in the population, numerous studies have focused on the control of GLUT4 expression and availability (5). GLUT4 is retained in microsomes and upon insulin stimulus it translocates to plasma membrane (PM) of skeletal, cardiac, and adipose cells, where it regulates the glucose transport, providing substrates for the cell metabolism (6).
Besides GLUT4, which accounts for the majority of postprandial glucose uptake, playing a key role in whole-body glucose homeostasis, the expression of other GLUTs is also increased by THs, specifically GLUT1 and GLUT3 $(7,8)$. These are low-Km transporters expressed in many tissues; they are responsible for the glucose uptake in the unfed state.

Intriguingly, both hypothyroidism and hyperthyroidism are accompanied by glucose intolerance, and the underlying basis of these phenomena is not well understood $(9,10)$. In fact, in hyperthyroid states, in parallel to the increased glucose consumption $(11,12)$, there is enhanced lipolysis, glycogenolysis, and gluconeogenesis, which by elevating plasma fatty acids and glucose levels might contribute for the decrease in

\footnotetext{
${ }^{1}$ Department of Physiology and Biophysics, Institute of Biomedical Sciences, University of São Paulo, São Paulo, Brazil.

${ }^{2}$ Division of Biochemistry, Central Drug Research Institute, Lucknow, India.

${ }^{3}$ Program in Cell Biology, Hospital for Sick Children, Toronto, Canada.

${ }^{4}$ Department of Biochemistry, University of Toronto, Toronto, Canada.
} 
insulin sensitivity $(13,14)$. Whether these processes are the underlying cause or only a consequence of the insulin resistance found in hyperthyroidism is unknown, but they certainly contribute to an impairment of insulin sensitivity. These effects occur under chronically high levels of THs, which contrasts with data obtained in our laboratory, which show that the acute triiodothyronine $\left(\mathrm{T}_{3}\right)$ administration, in rats, increases GLUT4 expression and content in isolated PM from muscle tissue, as well as the glucose decay rate (15). This event was established in a short period of time (30 minutes), and was ascribed to nongenomic action of THs. These data also support in vitro studies showing that $\mathrm{TH}$ rapidly increases glucose uptake by myocytes (16). However, it is still to be determined if this effect of $\mathrm{T}_{3}$ is entirely dependent on GLUT4, or is resultant of alterations in insulin sensitivity.

The present study attempted to investigate these possibilities, by evaluating the effects of acute $\mathrm{T}_{3}$ administration on glucose uptake in L6 cells transfected with myc-tagged Slc2a4 or myc-tagged Slc2a1, in the presence or absence of insulin.

\section{Materials and Methods}

\section{Materials}

$\mathrm{T}_{3}$, 2-deoxy-D-glucose (2-DG), Triton X-100, cytochalasin B, antibody anti-c-myc, O-phenylenediamine dihydrochloride, and protease inhibitor cocktail were purchased from Sigma Chemical Co. (St. Louis, MO). 2-Deoxy-D-[3H] glucose was from PerkinElmer (Boston, MA). Human insulin (Humulim R) was from Eli Lilly Canada (Toronto, Ontario, Canada). Pierce BCA Protein Detection Kit was from Thermo Fisher Scientific (Rockford, IL). Sulfo-NHS-SS-biotin and Streptavidin agarose beads were purchased from Pierce (Rockford, IL). Antibodies to phospho-Akt (Ser473), GLUT4, and GLUT3 were from Cell Signaling Technology (Danvers, MA). Polyclonal anti-myc antibody was obtained from Santa Cruz Biotechnology, Inc. (Santa Cruz, CA). AG1-X8 resin was purchased from Bio-Rad Laboratories Ltd. (Toronto, Ontario, Canada). Minimum essential medium ( $\alpha$-MEM), fetal bovine serum (FBS), antibiotic/antimycotic solution, and trypsinethylenediaminetetraacetic acid (EDTA) were obtained from Invitrogen (Carlsbad, CA).

\section{Cell culture}

L6-GLUT4myc, L6-GLUT1myc, and wild-type L6 cells were used in the experiments. The L6 cells transfected with c-myc-tagged Slc2a4 (L6-GLUT4myc) and c-myc-tagged Slc2a1 (L6-GLUT1myc) were used as previously described (17-19). These myoblasts, upon reaching confluence in low serum, differentiate into myotubes. The cells were cultured in $\alpha$-MEM supplemented with $10 \%$ FBS, 100 units / $\mathrm{mL}$ penicillin, and $100 \mu \mathrm{g} / \mathrm{mL}$ streptomycin and were grown at $37^{\circ} \mathrm{C}$ in $95 \%$ humidified air with $5 \% \mathrm{CO}_{2}$. Cells at $80 \%$ confluence were resuspended and plated until reaching $80 \%$ confluence; after that, they were cultured for 6 days in $\alpha$-MEM and $2 \%$ FBS to induce the L6 differentiation. For experiments, cells were maintained in (a) normal FBS (control group), (b) FBS depleted of THs for 24 hours (hypothyroid [Tx] group), (c) FBS depleted of THs for 24 hours and then incubated with $\mathrm{T}_{3}\left(10^{-6}\right.$ to $10^{-9} \mathrm{M}$ ) for 10-40 minutes and, (d) FBS depleted of THs for 24 hours and then incubated with insulin $(10,20$, and $100 \mathrm{nM})$ alone or with $\mathrm{T}_{3}\left(10^{-8} \mathrm{M}\right)$ for 30 minutes. TH depletion from FBS was carried out according to Samuels et al. (20).

\section{2-DG uptake}

After $\mathrm{T}_{3}$ treatment, glucose uptake into L6-GLUT4myc and L6-GLUT1myc myotubes was assessed for 5 minutes in HEPES-buffered saline (140 mM NaCl, $20 \mathrm{mM}$ HEPES, $5 \mathrm{mM}$ $\mathrm{KCl}, 2.5 \mathrm{mM} \mathrm{MgSO}_{4}$, and $1 \mathrm{mM} \mathrm{CaCl}_{2}$ [pH 7.4]) containing $10 \mu \mathrm{M} 2-\mathrm{DG}(0.5 \mu \mathrm{Ci} / \mathrm{mL} 2-[3 \mathrm{H}] \mathrm{DG})$ at room temperature as described by Huang et al. (21). Nonspecific uptake was determined in the presence of cytochalasin B $(10 \mu \mathrm{M})$. 2-DG uptake was also determined in GLUT4myc and GLUT1myc L6 cells treated with insulin $(100 \mathrm{nM})$, and used as a positive assay control.

\section{Optical detection of GLUT4myc and GLUT1myc at the cell surface}

Following the $T_{3}$ treatment, surface GLUT4myc or GLUT1myc levels were determined in nonpermeabilized L6-GLUT4myc or GLUT1myc myotubes. Briefly, cells were washed in ice-cold phosphate-buffered saline (PBS) supplemented with $1 \mathrm{mM} \mathrm{CaCl}$ and $1 \mathrm{mM} \mathrm{MgCl}_{2}$ ( $\mathrm{mH} 7.4$ ), fixed in $3 \%$ paraformaldehyde for 30 minutes, quenched with $100 \mathrm{mM}$ glycine for 10 minutes, blocked with $5 \%$ goat serum for 15 minutes, and incubated with anti-myc antibody solution $\left(1.0 \mu \mathrm{g} / \mathrm{mL}\right.$ in PBS with $3 \%$ goat serum) for one hour at $4^{\circ} \mathrm{C}$. After labeling, excess antibody was removed by extensive washing in ice-cold PBS. Cell-surface-bound antibodies were detected by horseradish-peroxidase-conjugated secondary antibodies followed by peroxide detection with O-phenylenediamine, as described by Wang et al. (22). GLUT4myc and GLUT1myc at the cell surface were also evaluated in L6 cells treated with insulin $(100 \mathrm{nM})$, and used as a positive assay control.

\section{Detection of GLUT4 and GLUT3 at the cell surface by biotinylation}

Cell surface biotinylation was performed in wild-type L6 cells as a modification of a method described previously (23). Following the $\mathrm{T}_{3}$ treatment, surface GLUT4 and GLUT3 contents were determined in wild-type L6 myotubes. Cells were grown in six-well plates to $80 \%$ confluence, washed with PBS/CM (PBS with $0.1 \mathrm{mM} \mathrm{CaCl} 2$ and $1 \mathrm{mM} \mathrm{MgCl}$ ), and incubated twice for 20 minutes at $4^{\circ} \mathrm{C}$ with $1.0 \mathrm{mg} / \mathrm{mL}$ sulfosuccinimidyl-2-(biotinamido)ethyl-1,3-dithiopropionate (Sulfo-NHS-SS-biotin) in $20 \mathrm{mM}$ HEPES (pH 8.5), $2 \mathrm{mM}$ $\mathrm{CaCl}_{2}$, and $150 \mathrm{mM} \mathrm{NaCl}$. Cells were washed twice for 20 minutes with PBS/CM-containing $100 \mathrm{mM}$ glycine at $4^{\circ} \mathrm{C}$ and lysed with $1 \%$ sodium dodecyl sulfate (SDS) in $150 \mathrm{mM} \mathrm{NaCl}$, $5 \mathrm{mM}$ EDTA, $1 \%$ of Triton X-100, and $50 \mathrm{mM}$ Tris (pH 7.5) containing protease inhibitors, and referred to as buffer A. Samples were diluted $10 \times$ with buffer A without SDS. Streptavidin agarose beads were added to the lysate and incubated overnight at $4^{\circ} \mathrm{C}$. The next day the lysate was centrifuged at $14,000 \mathrm{~g}$ for 5 minutes to separate beads from the supernatant. Beads were washed $3 \times$ with buffer $\mathrm{A}$ without SDS and $2 \times$ with high-ionic-strength buffer $(500 \mathrm{mM}$ $\mathrm{NaCl}, 0.1 \%$ Triton $\mathrm{X}-100,5 \mathrm{mM}$ EDTA, and $50 \mathrm{mM}$ Tris- $\mathrm{HCl}$ [pH 7.5]). The final wash was done with $50 \mathrm{mM}$ Tris- $\mathrm{HCl}(\mathrm{pH}$ 7.5). Beads were resuspended in sample buffer, heated for 5 minutes at $75^{\circ} \mathrm{C}$, and analyzed by SDS-polyacrylamide gel electrophoresis (PAGE) and immunoblotting with antiGLUT4 (1:4000) and anti-GLUT3 (1:4000) expression. 
Glyceraldehyde 3-phosphate dehydrogenase and insulin receptor were used as loading control of total and PM expression of GLUT4 and GLUT3, respectively. The band detection was performed using the Enhanced Chemiluminescence (ECL) kit (Amersham Biosciences, Buckinghamshire, United Kingdom). Blots were analyzed with Scion Image software (Scion Corp., Frederick, MD). Results were expressed as arbitrary units.

\section{Evaluation of total and phosphorylated Akt content}

After indicated treatments, L6-GLUT4myc myotubes were washed with ice-cold PBS; lysed in 1\% Triton X-100 in PBS supplemented with $\mathrm{NaOV}_{3}(1 \mathrm{mM}), \mathrm{NaF}(1 \mathrm{mM})$, and protease inhibitor cocktail (1:1000); and further analyzed by SDSPAGE and immunoblotting with anti-p-Akt Ser 473 (1:1000). The band detection was performed as previously described.

\section{Statistical analysis}

Results are expressed as mean \pm standard error of the mean and subjected to analysis of variance, followed by the Student-Newman-Keuls. Differences were considered significant at $p<0.05$.

\section{Results}

\section{$T_{3}$ action on 2-DG transport}

Glucose uptake in L6-GLUT4myc cells is determined by GLUT4 $(18,19)$. Figure 1 illustrates the dose-response and time course of glucose uptake in L6-GLUT4myc myotubes. Group Tx displayed reduced glucose uptake compared with the control (C) group. $T_{3}$ treatment for 30 minutes, in doses from $10^{-9}$ to $10^{-6} \mathrm{M}$, promoted an increase of glucose uptake in comparison to the Tx group (Fig. 1A). The $10^{-8} \mathrm{M} \mathrm{T}_{3}$ dose was used for all subsequent studies. Figure $1 \mathrm{~B}$ shows that glucose uptake in L6-GLUT4myc cells significantly rose by 30 minutes of $\mathrm{T}_{3}$ treatment and continued to increase at
40 minutes. As expected, insulin administration also increased glucose uptake.

\section{$T_{3}$ effect on total and PM surface GLUT4 content in L6-GLUT4myc and wild-type cells}

Figure 2A and B shows the total amount of GLUT4 on L6 wild-type and L6-GLUT4myc cells, respectively. Total GLUT4 content was not altered in $\mathrm{Tx}$ and $\mathrm{T}_{3}$-treated in comparison to the control group. GLUT4 and GLUT4myc present in the PM of wild-type L6 and L6-GLUT4myc myotubes were reduced in $T x$ in comparison to control group. $T_{3}$ administration did not induce any change in this parameter for up to 30 minutes of treatment (Fig. 2C, D). However, by 40 minutes, surface GLUT4myc rose, reaching the levels observed in the control group (Fig. 2D). Figure 2D also shows an increase of the surface GLUT4myc content in response to insulin administration, as expected.

\section{$T_{3}$ effect on phosphorylated protein kinase $B$ content}

The phosphorylation of protein kinase $\mathrm{B}(\mathrm{AKT} / \mathrm{PKB})$ is a key step for GLUT4 translocation induced by insulin in muscle cells (24). The data presented in Figure 3 show that $\mathrm{T}_{3}$ did not change the phosphorylated AKT/PKB content in L6GLUT4myc cells, whereas insulin increased it, as expected.

\section{$T_{3}$ is additive to the stimulatory effect of insulin on 2-DG transport without altering GLUT4myc content}

Insulin is a known stimulator of glucose uptake into muscle tissue and muscle cells, a task accomplished by translocation of GLUT4 from intracellular stores to the cell surface $(25,26)$. However, the possible interaction between THs and insulin on these processes has not been examined. Here, we used L6GLUT4myc cells to explore the effect of acute administration of these hormones on glucose uptake and surface GLUT4 content. Strikingly, Tx cells co-incubated with $\mathrm{T}_{3}$ and insulin
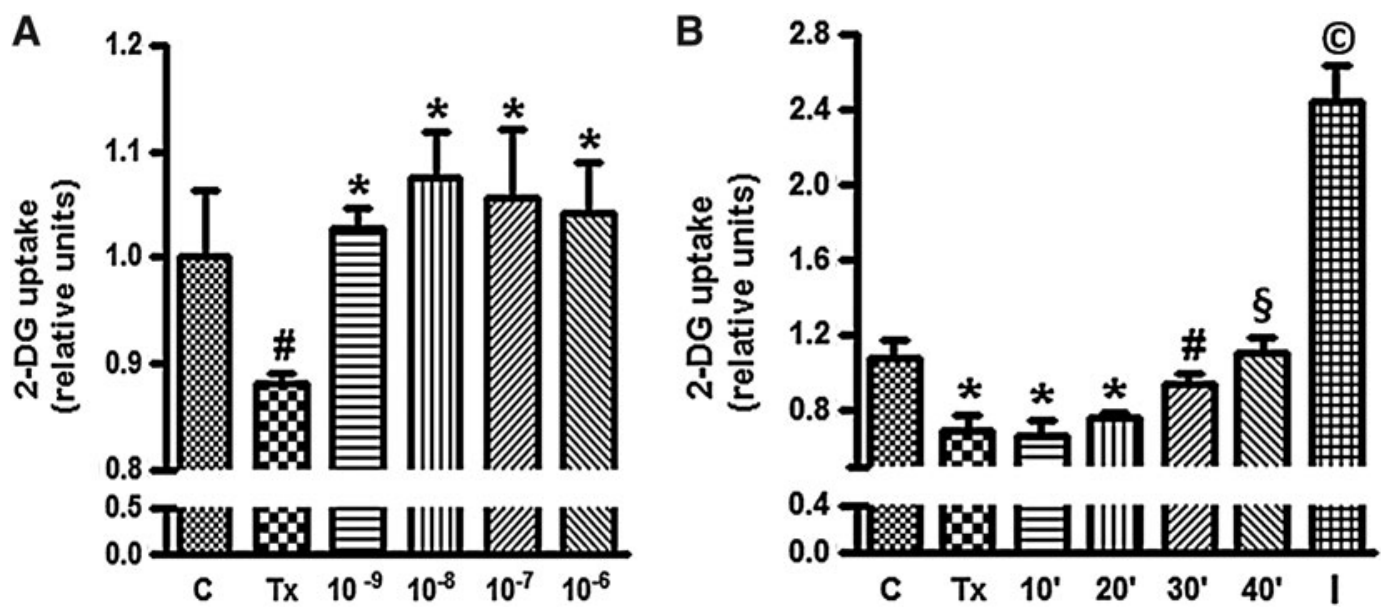

FIG. 1. Dose-response and time course study of $T_{3}$ on glucose transport. Panel (A) shows the dose-response curve and panel (B) shows the time course study for evaluating 2-DG uptake. L6-GLUT4myc cells were segregated into the following groups: control (C); hypothyroid (Tx); Tx treated with $\mathrm{T}_{3}\left(10^{-6}, 10^{-7}, 10^{-8}\right.$, and $\left.10^{-9} \mathrm{M}\right)$ for $10,20,30$, and 40 minutes; and control treated with insulin (I) for 20 minutes. The data present means $\pm S E M$ of three independent experiments $(n=3$ per experiment), expressed in relative units. Panel (A) ${ }^{\#} p<0.05$ versus C, ${ }^{*} p<0.05$ versus Tx; panel (B) ${ }^{*} p<0.01$ versus C, ${ }^{\#} p<0.05$ versus Tx and Tx T -treated for 10 minutes, ${ }^{\S} p<0.05$ versus Tx and Tx $\mathrm{T}_{3}$-treated for 10 and 20 minutes, ${ }^{\circ} p<0.005$ versus all groups. $\mathrm{T}_{3}$, triiodothyronine; 2-DG, 2-deoxy-D-glucose; SEM, standard error of the mean; GLUT4, glucose transporter 4. 


\section{A}
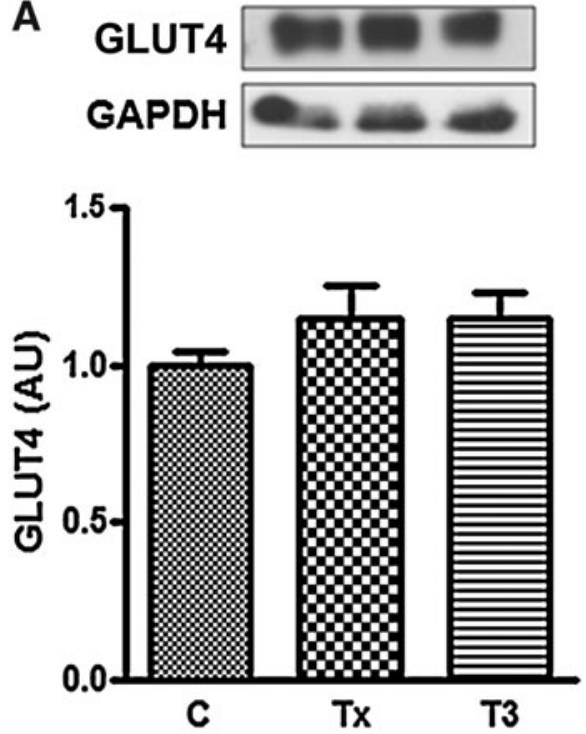

B
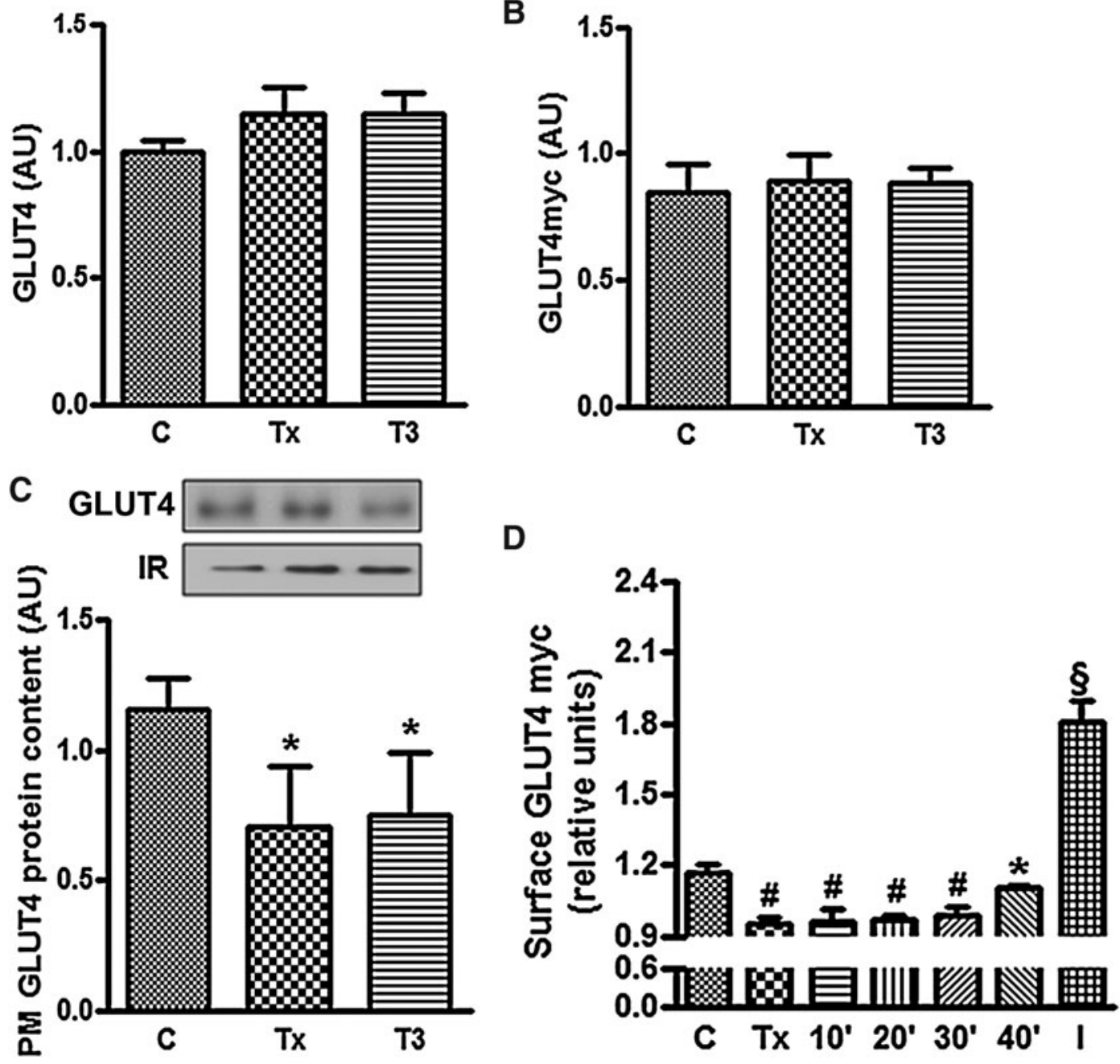

FIG. 2. Effect of $T_{3}$ treatment on total GLUT4 content and on the amount of GLUT4 present in the plasma membrane. Panels (A and B) show the total amount of GLUT4 in wild-type L6 cells and L6-GLUT4myc, respectively. Panels (C and D) show the amount of GLUT4 present in the plasma membrane, in wild-type L6 cells and L6-GLUT4myc, respectively. Wild-type L6 and L6-GLUT4myc cells were segregated into the following groups: control; hypothyroid; Tx treated with $\mathrm{T}_{3}\left(10^{-8} \mathrm{M}\right)$ for $10,20,30$, and 40 min; and control treated with insulin for $20 \mathrm{~min}$. The total GLUT4 amount was determined by western blotting and the amount of GLUT4 present in surface of plasma membrane was determined by biotinylation followed by western blotting and by optical detection, as described in the Materials and Methods section. At the top of panels (A and C), typical autoradiograms of one experiment in a total of three are shown. The data show means \pm SEM of three independent experiments ( $n=3$ per experiment). Panel (C) ${ }^{*} p<0.05$ versus $C$; panel (D) ${ }^{\#} p<0.01$ versus C, ${ }^{*} p<0.05$ versus Tx, ${ }^{\S} p<0.05$ versus all groups. AU, arbitrary unit; IR, insulin receptor.

$(10,20$, and $100 \mathrm{nM})$ for 30 minutes displayed enhanced glucose uptake compared with Tx cells treated only with insulin at the same doses (Fig. 4A). The major effect of $\mathrm{T}_{3}$ was observed with the highest dose of insulin $(100 \mathrm{nM})$. In stark contrast, surface GLUT4myc content remained unchanged with or without $\mathrm{T}_{3}$ administration, and even decreased when $\mathrm{T}_{3}$ was present along with the highest dose of insulin (Fig. 4B).

Time course of $T_{3}$ on 2-DG transport and surface GLUT1myc content in L6-GLUT1myc cells

In L6-GLUT1myc cells, glucose uptake is vastly governed by GLUT1, whereas in L6-GLUT4myc, GLUT4 is the defining route of glucose entry (19). Hence, these cells offer the opportunity to compare the effects of Tx on the two transporters. As observed with L6-GLUT4myc cells, L6-GLUT1myc cells cultured in Tx showed reduced glucose uptake (Fig. 5A), and reduced surface GLUT1myc content (Fig. 5B) compared with control (C) cells. However, in these cells, $\mathrm{T}_{3}$ treatment from 10 to 40 minutes did not alter either parameter. These results highlight that the effect of $\mathrm{T}_{3}$ is specific for the GLUT4 transporter.

\section{$T_{3}$ effect on total and PM GLUT3 content}

Although GLUT4 is the most important GLUT protein in muscle cells, myocytes also express GLUT1 and GLUT3 (27). 


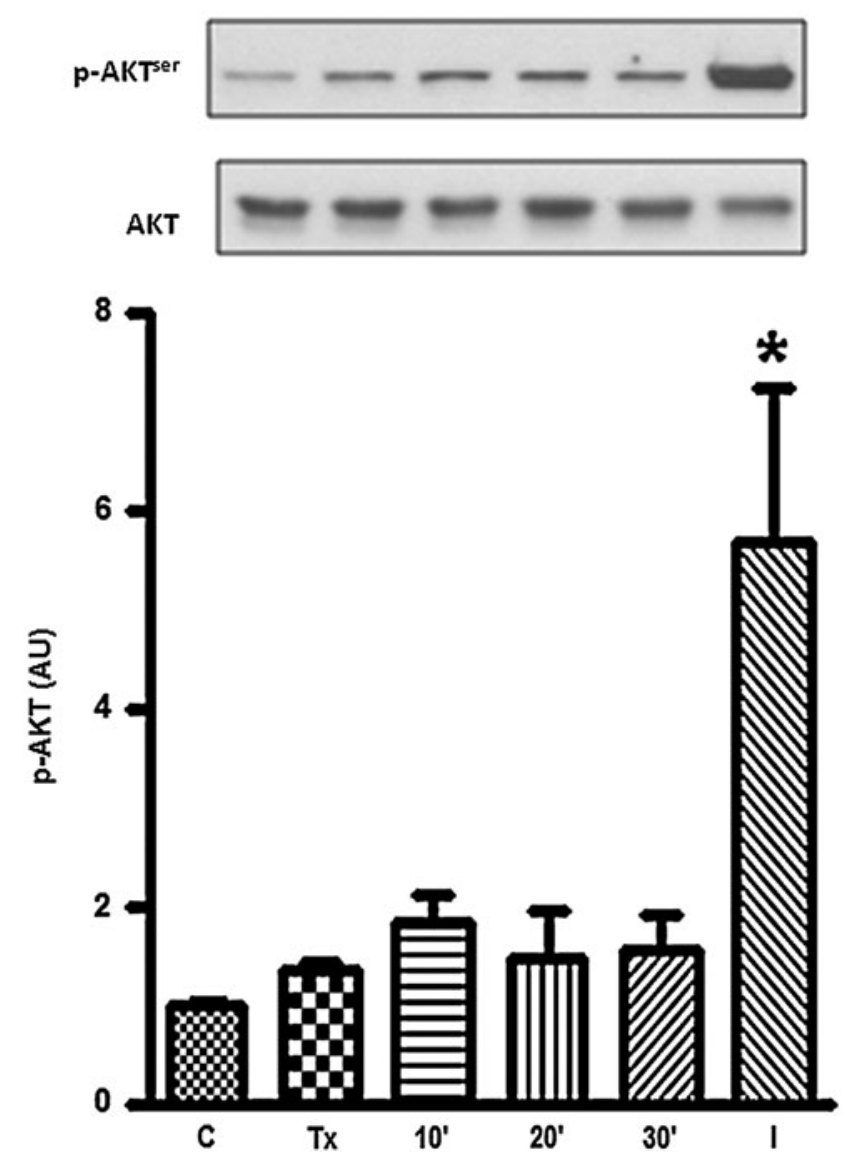

FIG. 3. $\mathrm{T}_{3}$ effect on $\mathrm{AKT} / \mathrm{PKB}$ phosphorylation. L6GLUT4myc cells were segregated into the following groups: control; hypothyroid; $\mathrm{Tx}$ treated with $\mathrm{T}_{3}\left(10^{-8} \mathrm{M}\right)$ for 10,20 , and $30 \mathrm{~min}$; and control treated with insulin for $20 \mathrm{~min}$. At the top, typical autoradiograms of one experiment in a total of three are shown. The respective graphical representation obtained in all experiments is shown at the bottom. The data show means \pm SEM ( $n=3$ per experiment), expressed in AUs. ${ }^{*} p<0.05$ versus all group. AKT/PKB, protein kinase $\mathrm{B}$.

Considering that $\mathrm{T}_{3}$ increased glucose uptake without altering GLUT4 and GLUT1 content at PM, we used L6 wild-type cells to explore whether acute administration of $T_{3}$ affects PM GLUT3 content. Figure 6 shows that although $T_{3}$ rapidly increased the total GLUT3 content, it did not change the amount of GLUT3 present at the PM.

\section{Discussion}

THs play an important role in the control of glucose homeostasis; however, the mechanisms involved in these actions have not been thoroughly explored. $\mathrm{T}_{3}$ upregulates the transcription of some GLUTs, notably GLUT4, leading to an increase in glucose uptake by muscle and adipose cells $(28,29)$. However, in hyperthyroid states, in parallel to the high glucose peripheral utilization, hepatic glucose output is increased, as a result of the high glucose hepatic production and GLUT2 expression (30,31); this leads to glucose intolerance (14). In fact, insulin resistance is well established in hyperthyroidism (14). Glucose intolerance is also observed in hypothyroidism, as a result of the decreased energy expenditure and GLUT4 expression, among other factors (9,11,32). All these events were shown to be dependent on $\mathrm{TH}$ action at the level of gene transcription.

On the other hand, THs can also act nongenomically to increase glucose uptake into heart slices (16). Glucose uptake in heart, skeletal muscle, and adipose tissue is carried out mainly by GLUT4, the major GLUT present in these tissues. In response to insulin or muscle contraction, GLUT4 is rapidly translocated and inserted into the PM. However, it was not known whether THs can also regulate this mechanism. Here, we tested the hypothesis that THs may exert an acute, nongenomic action regulating GLUT4 translocation in skeletal muscle cells. To this end we used L6-GLUT4myc cells and wild-type L6 cells that allowed us to evaluate the amount of GLUT4 inserted into the PM by different methodological approaches $(22,23)$.

As expected, L6-GLUT4myc cells kept in culture medium in the absence of $\mathrm{T}_{3}$ displayed lower glucose uptake and lower GLUT4myc protein content at the cell surface compared with control cells. Moreover, $\mathrm{T}_{3}$ treatment itself stimulated glucose transport into L6-GLUT4myc cells within 30 minutes, even though an increase of GLUT4myc protein content at PM was observed only when $\mathrm{T}_{3}$ treatment was performed for longer period of time (40 minutes). Moreover, the absence of $T_{3}$ as well as $\mathrm{T}_{3}$ treatment did not alter the total amount of GLUT4 protein. The same pattern was observed in wild-type L6 cells concerning the amount of total GLUT4 and GLUT4 content at PM 30 minutes after $T_{3}$ treatment.

Because glucose uptake in L6-GLUT4myc cells is vastly dependent on GLUT4, these results lead us to speculate that the increased glucose uptake in response to $T_{3}$ treatment within 30 minutes may be due to the activation of GLUT4 already present in the PM, a step that is also regulated under diverse conditions $(33,34)$. However, we cannot formally exclude that an unrelated GLUT is recruited by $\mathrm{T}_{3}$ treatment. Beyond this initial (30 minutes) action of $T_{3}$, the subsequent rise in surface GLUT4 content detected by 40 minutes suggests that $\mathrm{T}_{3}$ can also increase glucose uptake by promoting GLUT4 translocation.

In this sense the second salient finding of this study is that the stimulation of glucose uptake by $\mathrm{T}_{3}$ was additive to that of insulin when both hormones were present for 30 minutes, and this increase occurred without a further gain in surface GLUT4myc levels beyond those increased by insulin. In fact, the major additive action of insulin-stimulated glucose uptake by $\mathrm{T}_{3}$ occurred with the highest dose of insulin tested $(100 \mathrm{nM})$, even though under these conditions surface GLUT4myc even dropped. These findings reinforce the concept that $T_{3}$ increases glucose uptake independently of GLUT4 translocation and that $\mathrm{T}_{3}$ might improve insulin action in these cells by mechanisms that do not depend on GLUT4 translocation.

GLUT4 insertion at the surface of insulin-responsive cells involves the activation of intracellular signaling pathways initiated by insulin interaction with its receptors at the PM, and further activation of phosphoinositide kinase-3 and AKT / PKB, which, in turn, leads to GLUT4 translocation and insertion in the PM (26). Our results, demonstrating that the absence or presence of $\mathrm{T}_{3}$ did not change the phosphorylation of $\mathrm{AKT} / \mathrm{PKB}$, reinforces that $\mathrm{T}_{3}$ improved glucose uptake independently of insulin action.

Indeed, in vivo studies from our laboratory have shown that $\mathrm{T}_{3}$ rapidly increases GLUT4 translocation and glucose decay 
A

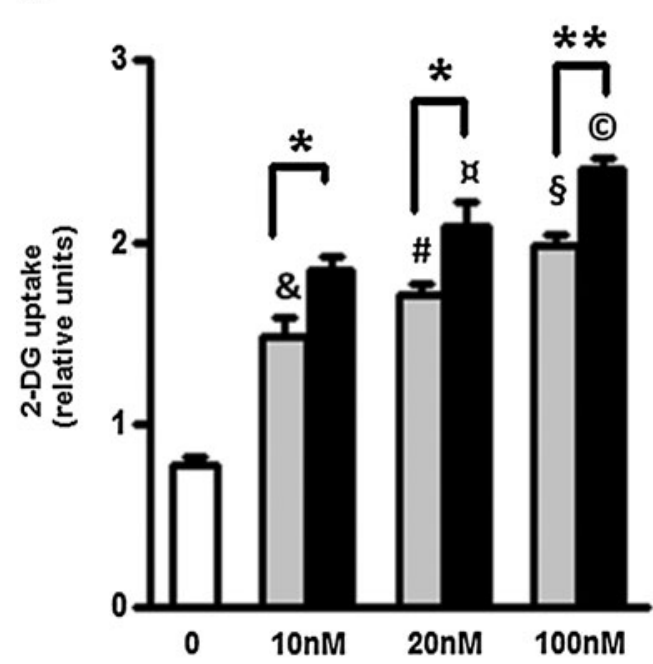

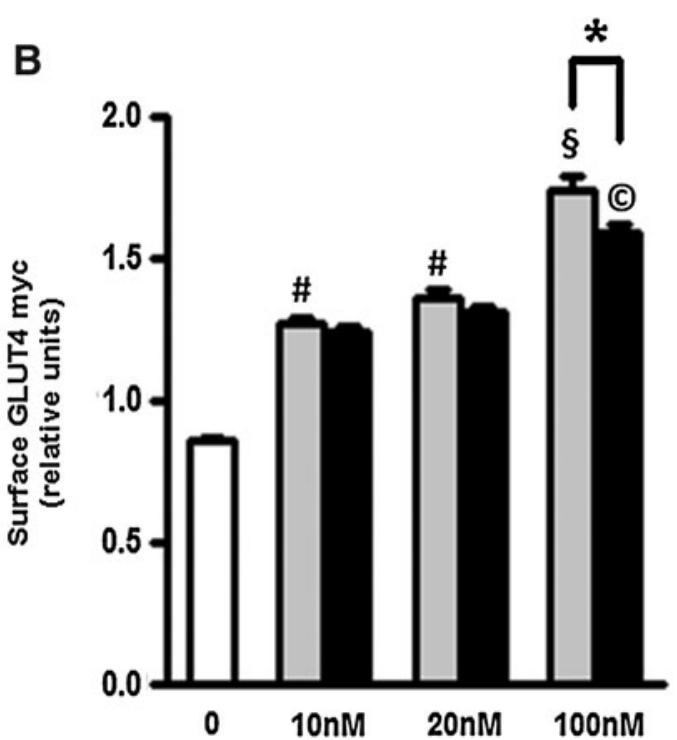

FIG. 4. Effect of $\mathrm{T}_{3}$ treatment on insulin-induced glucose transport. Panel (A) shows 2-DG uptake and panel (B) shows surface GLUT4 levels. L6-GLUT4myc cells were segregated into the following groups: hypothyroid ( $\square$ ), Tx insulin-treated $(10,20$, and $100 \mathrm{nM})(\square)$, and Tx treated with the same doses of insulin plus $\mathrm{T}_{3}\left(10^{-8} \mathrm{M}\right)$ for $30 \mathrm{~min}(\square)$. The amount of GLUT4 present in surface of plasma membrane was determined by optical detection, as described in the Materials and Methods section. The data show means \pm SEM of three independent experiments ( $n=3$ per experiment), expressed in relative units. Panel (A) ${ }^{*} p<0.05 ;{ }^{* *} p<0.01 ;{ }^{\&} p<0.05$ versus $0 ;{ }^{*} p<0.05$ versus 0 and $10 \mathrm{nM} ;{ }^{\S} p<0.05$ versus 0,10 , and $20 \mathrm{nM}$; ${ }^{a} p<0.05$ versus 0 and $10 \mathrm{nM} ;{ }^{\circ} p<0.05$ versus 0,10 , and $20 \mathrm{nM}$. Panel (B) ${ }^{*} p<0.001 ;{ }^{\#} p<0.05$ versus 0 ; ${ }^{\S} p<0.05$ versus 0 , 10 , and $20 \mathrm{nM}$; ${ }^{\odot} p<0.05$ versus 0,10 , and $20 \mathrm{nM}$.

rate in the Tx rat (15). Further, $\mathrm{T}_{3}$ decreased the phosphorylation of $\mathrm{AKT} / \mathrm{PKB}$ in skeletal muscles, and did not change the serum insulin concentration that was reduced in Tx rats (Supplementary Data; available online at www.liebertonline .com/thy). These data strengthen our in vitro results presented herein indicating that $\mathrm{T}_{3}$ action does not depend on insulin signaling pathway.

Although GLUT4 is the major GLUT of skeletal muscle, myocytes also express GLUT1 and GLUT3 that could potentially be involved in the increased glucose uptake induced by
$\mathrm{T}_{3}$ (27). In fact, Slc2a1 and Slc2a3 gene expression is upregulated by THs $(7,35,36)$. We tested $\mathrm{T}_{3}$ action in L6-GLUT1myc cells, in which glucose uptake is mainly dependent on GLUT1. Although L6-GLUT1myc cells cultured in a $T_{3}$-free medium exhibited lower glucose uptake in comparison to control cells, $\mathrm{T}_{3}$ addition for 30 minutes did not alter this parameter. Similarly, surface GLUT1myc levels were unchanged upon $T_{3}$ treatment. These findings indicate that GLUT1 protein is not involved in the stimulatory effect of $T_{3}$ on glucose uptake into L6 cells and that within this time there
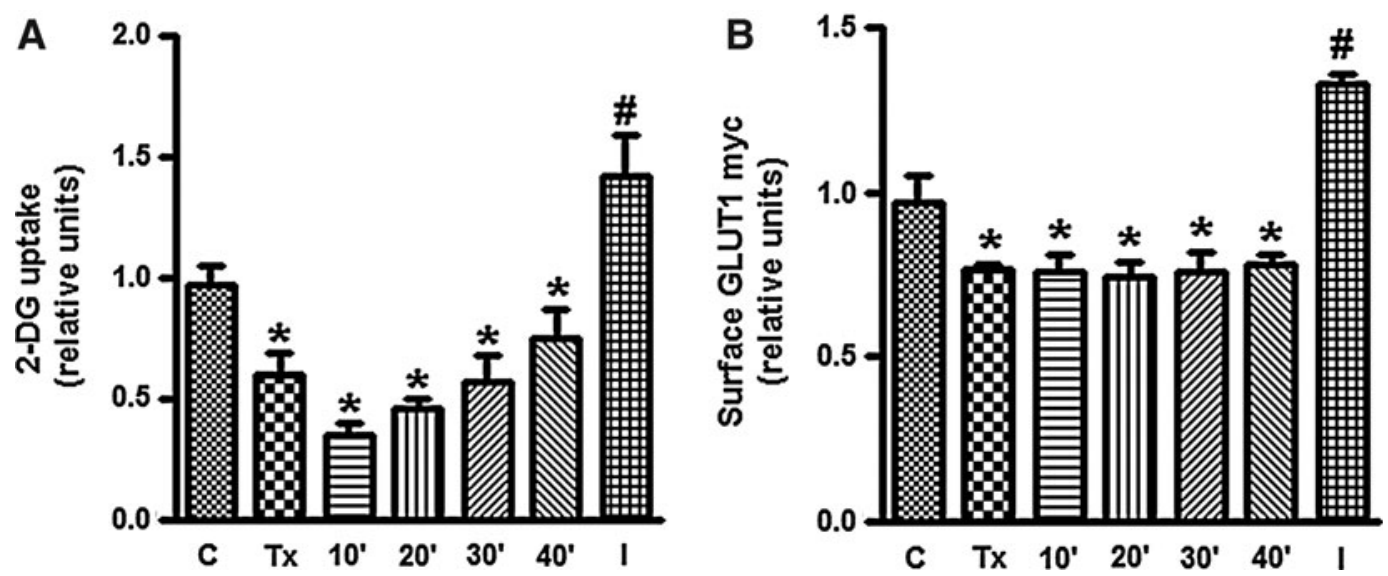

FIG. 5. Effect of $\mathrm{T}_{3}$ treatment on glucose transport and surface GLUT1. Panel (A) shows 2-DG uptake and panel (B) shows surface GLUT1 levels. L6-GLUT1myc cells were segregated into the following groups: control; hypothyroid; Tx treated with $\mathrm{T}_{3}\left(10^{-8} \mathrm{M}\right)$ for $10,20,30$, and $40 \mathrm{~min}$; and control treated with insulin for $20 \mathrm{~min}$. The amount of GLUT1 present in surface of plasma membrane was determined by optical detection, as described in the Materials and Methods section. The data show means \pm SEM of two independent experiments ( $n=3$ per experiment), expressed in relative units. Panel (A) and Panel (B) ${ }^{*} p<0.05$ versus $C ;{ }^{*} p<0.05$ versus all groups. 
A
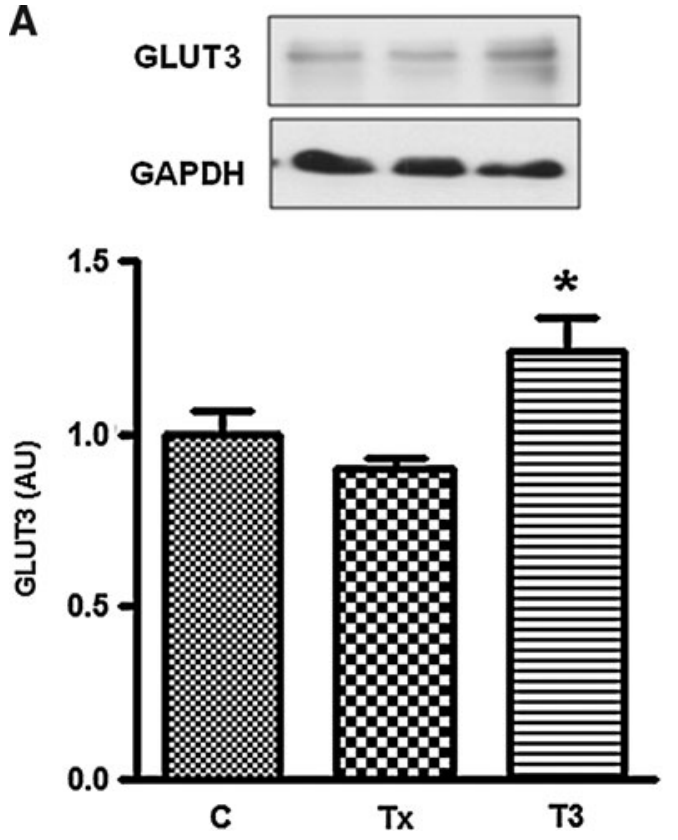

B
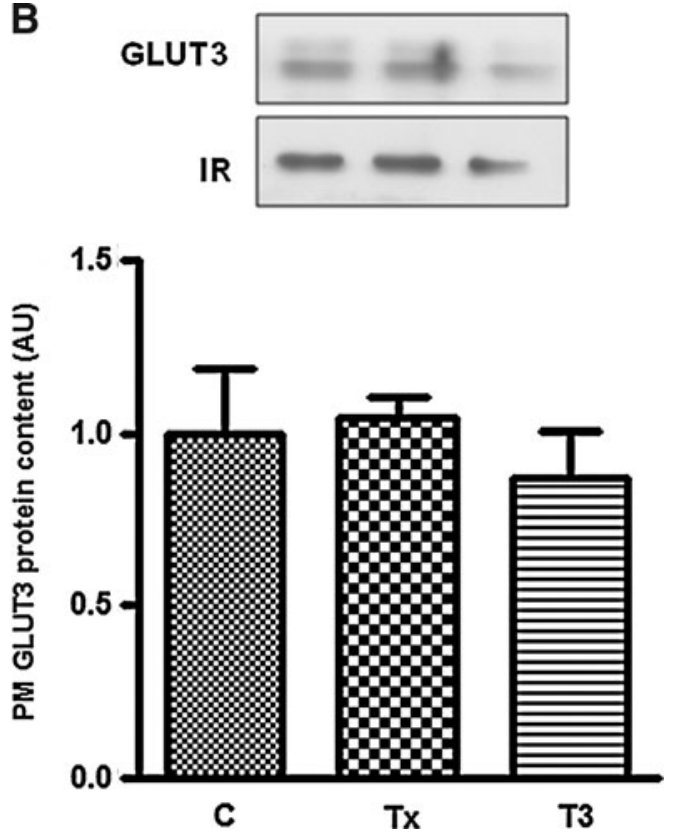

FIG. 6. $T_{3}$ effect on total GLUT3 content and on the amount of GLUT3 present in the plasma membrane. Panel (A) shows the total GLUT3 content and panel (B) shows the amount of GLUT3 present in the plasma membrane. Wild-type L6 cells were segregated into the following groups: control, hypothyroid, and Tx treated with $\mathrm{T}_{3}\left(10^{-8} \mathrm{M}\right)$ for $30 \mathrm{~min}\left(\mathrm{~T}_{3}\right)$. The total GLUT3 amount was determined by western blotting and the amount of GLUT3 present in the plasma membrane was determined by biotinylation followed by western blotting, as described in the Materials and Methods section. At the top of panels (A and B), typical autoradiograms of one experiment in a total of three are shown. The data show means \pm SEM of three independent experiments ( $n=3$ per experiment), expressed in AUs. ${ }^{*} p<0.05$ versus Tx.

is no change in the net levels of the endogenous GLUT1 protein that might contribute to glucose uptake.

Even though little is known about the relationship between $\mathrm{T}_{3}$ and GLUT3, and that most of the studies were performed in brain of neonates, it is worth to comment that increased GLUT3 content in the PM was shown to occur in monocytes of hyperthyroid patients (7). Therefore, to assess the involvement of GLUT3 in the $T_{3}$ effects just described, we have used wild-type L6 cells. Our data showed that $\mathrm{T}_{3}$ increased total GLUT3 content; however, it did not alter the amount of GLUT3 at the PM; this supports the hypothesis that $T_{3}$ increased glucose uptake independently of GLUT translocation.

In summary, $\mathrm{T}_{3}$ stimulates glucose uptake into muscle cells within 30 minutes via nongenomic mechanisms and without any gain in surface GLUT4, GLUT1, or GLUT3. Moreover, $\mathrm{T}_{3}$ itself enhances, as well as has an additive effect, on insulin action on glucose transport into cells, reinforcing data from the literature $(37,38)$. Beyond 30 minutes, the stimulation of glucose uptake by $\mathrm{T}_{3}$ may also result from GLUT4 translocation to the cell membrane. The fact that glucose uptake induced by $\mathrm{T}_{3}$ was only observed in L6-GLUT4myc, but not in L6-GLUT1myc cells, strongly indicates that GLUT4 is involved in this effect. We hypothesize that $\mathrm{T}_{3}$-induced glucose transport might depend on conformational changes that could lead to enhancement of GLUT4 activity.

\section{Acknowledgments}

F.G.S. and S.S.T. are the recipients of the Fundação de Amparo à Pesquisa do Estado de São Paulo (FAPESP: 08/ 56446-9 and 2006/52830-3, respectively) fellowships. M.T.N. is the recipient of Conselho Nacional de Pesquisa e Desenvolvimento (CNPq) fellowship, Brazil. This work was supported in part by grant MT 12601 from the Canadian Institutes of Health to A.K.

\section{Disclosure Statement}

The authors declare that no competing financial interests exist.

\section{References}

1. Sugden MC, Liu YL, Holness MJ 1990 Glucose utilization by skeletal muscles in vivo in experimental hyperthyroidism in the rat. Biochem J 271:421-425.

2. Chen-Zion M, Bassukevitz Y, Beitner R 1995 Rapid changes in carbohydrate metabolism in muscle induced by triiodothyronine; the role of glucose 1,6-biphosphate. Biochem Mol Med 56:19-25.

3. Casla A, Rovira A, Wells JA, Dohm GL 1990 Increased glucose transporter (GLUT4) protein expression in hyperthyroidism. Biochem Biophys Res Commun 171:182-188.

4. Shimizu Y, Shimazu T 2002 Thyroid hormone augments GLUT4 expression and insulin-sensitive glucose transport system in differentiating rat brown adipocytes in culture. J Vet Med Sci 64:677-681.

5. Kern M, Wells JA, Stephens JM, Elton CW, Friedman JE, Tapscott EB, Pekala PH, Dohm GL 1990 Insulin responsiveness in skeletal muscle is determined by glucose transporter (Glut4) protein level. Biochem J 270:397-400.

6. Foley K, Boguslavsky S, Klip A 2011 Endocytosis, recycling, and regulated exocytosis of glucose transporter 4. Biochemistry 50:3048-3061. 
7. Dimitriadis G, Maratou E, Alevizaki M, Boutati E, Psara K, Papasteriades C, Raptis SA 2005 Thyroid hormone excess increases basal and insulin-stimulated recruitment of GLUT3 glucose transporters on cell surface. Horm Metab Res 37:15-20.

8. Weinstein SP, Haber RS 1993 Glucose transport stimulation by thyroid hormone in ARL 15 cells: partial role of increased GLUT1 glucose transporter gene transcription. Thyroid 3:135142.

9. Peppa M, Koliaki C, Nikolopoulos P, Raptis SA 2010 Skeletal muscle insulin resistance in endocrine disease. J Biomed Biotechnol 2010:527850.

10. Roubsanthisuk W, Watanakejorn P, Tunlakit M, Sriussadaporn S 2006 Hyperthyroidism induces glucose intolerance by lowering both insulin secretion and peripheral insulin sensitivity. J Med Assoc Thai Suppl 5:S133-S140.

11. Matthaei S, Trost B, Hamann A, Kausch C, Benecke H, Greten H, Höppner W, Klein HH 1995 Effect of in vivo thyroid hormone status on insulin signalling and GLUT1 and GLUT4 glucose transport system in rat adipocytes. J. Endocrinol 144:347-357.

12. Weinstein SP, O’Boyle E, Haber RS 1994 Thyroid hormone increases basal and insulin-stimulated glucose transport in skeletal muscle. The role of GLUT4 glucose transporter expression. Diabetes 43:1185-1189.

13. Riis AL, Gravholt CH, Djurhuus CB, Nørrelund H, Jørgensen JO, Weeke J, Møller N 2002 Elevated regional lipolysis in hyperthyroidism. J Clin Endocrinol Metab 87:4747-4753.

14. Dimitriadis GD, Raptis SA 2001 Thyroid hormone excess and glucose intolerance. Exp Clin Endocrinol Diabetes 109 Suppl 2:S225-S239.

15. Brunetto EL, Teixeira SdaS, Giannocco G, Machado UF, Nunes MT 2012 T3 rapidly increases SLC2A4 gene expression and trafficking to the plasma membrane in skeletal muscle of rat and improves glucose homeostasis. Thyroid 22:70-79.

16. Segal J 1989 Acute effect of thyroid hormone on the heart: an extranuclear increase in sugar uptake. J Mol Cell Cardiol 21:323-334.

17. Ueyama A, Yaworsky KL, Wang Q, Ebina Y, Klip A 1999 GLUT-4myc ectopic expression in L6 myoblasts generates a GLUT-4-specific pool conferring insulin sensitivity. Am J Physiol 277(3 Pt 1):E572-E578.

18. Konrad D, Rudich A, Bilan PJ, Patel N, Richardson C, Witters LA, Klip A 2005 Troglitazone causes acute mitochondrial membrane depolarisation and an AMPK-mediated increase in glucose phosphorylation in muscle cells. Diabetologia 48:954-966.

19. Huang C, Somwar R, Patel N, Niu W, Török D, Klip A 2002 Sustained exposure of L6 myotubes to high glucose and insulin decreases insulin-stimulated GLUT4 translocation but upregulates GLUT4 activity. Diabetes 51:2090-2098.

20. Samuels HH, Stanley F, Casanova J 1979 Depletion of L3,5,3'-triiodothyronine and L-thyroxine in euthyroid calf serum for use in cell culture studies of the action of thyroid hormone. Endocrinology 105:80-85.

21. Huang C, Thirone AC, Huang X, Klip A 2005 Differential contribution of insulin receptor substrates 1 versus 2 to insulin signaling and glucose uptake in L6 myotubes. J Biol Chem 280:19426-19435.

22. Wang Q, Khayat Z, Kishi K, Ebina Y, Klip A 1998 GLUT4 translocation by insulin in intact muscle cells: detection by a fast and quantitative assay. FEBS Lett 427:193-197.

23. Riedel C, Levy O, Carrasco N 2001 Post-transcriptional regulation of the sodium/iodide symporter by thyrotropin. J Biol Chem 276:21458-21463.
24. Brozinick JT Jr., Birnbaum MJ 1998 Insulin, but not contraction, activates Akt/PKB in isolated rat skeletal muscle. MJJ Biol Chem 273:14679-14682.

25. Thong FS, Dugani CB, Klip A 2005 Turning signals on and off: GLUT4 traffic in the insulin-signaling highway. Physiology (Bethesda) 20:271-284.

26. Zaid H, Antonescu CN, Randhawa VK, Klip A 2008 Insulin action on glucose transporters through molecular switches, tracks and tethers. Biochem J 413:201-215.

27. Guillet-Deniau I, Leturque A, Girard J 1994 Expression and cellular localization of glucose transporters (GLUT1, GLUT3, GLUT4) during differentiation of myogenic cells isolated from rat foetuses. J Cell Sci 107:487-496.

28. Torrance CJ, Devente JE, Jones JP, Dohm GL 1997 Effects of thyroid hormone on GLUT4 glucose transporter gene expression and NIDDM in rats. Endocrinology 138:1204-1214.

29. Romero R, Casanova B, Pulido N, Suarez AL, Rodriguez E, Rovira A 2000 Stimulation of glucose transport by thyroid hormone in 3T3-L1 adipocytes: increased abundance of GLUT1 and GLUT4 glucose transporter proteins. J Endocrinol 164:187-195.

30. Klieverik LP, Janssen SF, Van Riel A, Foppen E, Bisschop $\mathrm{PH}$, Serlie MJ, Boelen A, Ackermans MT, Sauerwein HP, Fliers E, Kalsbeek A 2009 Thyroid hormone modulates glucose production via a sympathetic pathway from the hypothalamic paraventricular nucleus to the liver. Proc Natl Acad Sci U S A 106:5966-5971.

31. Weinstein SP, O'Boyle E, Fisher M, Haber RS 1994 Regulation of GLUT2 glucose transporter expression in liver by thyroid hormone: evidence for hormonal regulation of the hepatic glucose transport system. Endocrinology 135:649-654.

32. Wolf M, Weigert A, Kreymann G 1996 Body composition and energy expenditure in thyroidectomized patients during short-term hypothyroidism and thyrotropin-suppressive thyroxine therapy. Eur J Endocrinol 134:168-173.

33. Zaid H, Talior-Volodarsky I, Antonescu C, Liu Z, Klip A 2009 GAPDH binds GLUT4 reciprocally to hexokinase-II and regulates glucose transport activity. Biochem J 419:475-484.

34. Antonescu CN, Foti M, Sauvonnet N, Klip A 2009 Ready, set, internalize: mechanisms and regulation of GLUT4 endocytosis. Biosci Rep 29:1-11.

35. Ulisse S, Jannini EA, Pepe M, De Matteis S, D'Armiento M 1992 Thyroid hormone stimulates glucose transport and GLUT1 mRNA in rat Sertoli Cells. Mol Cell Endocrinol 87:131-137.

36. Santalucía T, Palacín M, Zorzano A 2006 T3 strongly regulates GLUT1 and GLUT3 mRNA in cerebral cortex of hypothyroid rat neonates. Mol Cell Endocrinol 251:9-16.

37. Prager C, Cross HS, Peterlik M 1990 Triiodothyronine stimulates 2-deoxy-D-glucose uptake by organ cultured embryonic chick small intestine. Acta Endocrinol (Copenh) 122:585-491.

38. Segal J, Schwartz H, Gordon A 1977 The effect of triiodothyronine on 2-deoxy-D-(1-3H) glucose uptake in cultured chick embryo heart cells. Endocrinology 101:143-149.

Address correspondence to: Maria Tereza Nunes, Ph.D. Department of Physiology and Biophysics Institute of Biomedical Sciences University of São Paulo Av. Prof. Lineu Prestes 1524 São Paulo, SP 05508-000 Brazil

E-mail: mtnunes@icb.usp.br 